\title{
Morphological characteristics and phylogenetic analyses of unusual morphospecies of Microcystis novacekii forming bloom in the Cheffia Dam (Algeria)
}

\author{
Soumaya EL HERRY ${ }^{1) *}$, Hichem NASRI ${ }^{1,3)}$ and Noureddine BOUAÏCHA ${ }^{1,2)}$ \\ ${ }^{1)}$ Laboratoire Santé Publique-Environnement, 5, Rue J.B. Clément, Université Paris-Sud 11, UFR de Pharmacie, 92296 Châtenay- \\ Malabry, France \\ ${ }^{2)}$ Actuel Address: Laboratoire Ecologie, Systématique et Evolution, UMR 8079, Université Paris-Sud 11, Bâtiment 362, 91405 Orsay \\ Cedex, France \\ ${ }^{3)}$ Institut de Biologie, Centre Universitaire d'El Taref, Algeria \\ *e-mail corresponding author: soumaya.herry@laposte.net
}

\begin{abstract}
The toxicological potential and morphological characteristics and phylogenetic analysis based on the 16S rDNA sequence and the 16S-23S rDNA internal transcribed spacer (ITS) were investigated in unusual morphospecies of Microcystis (MCYS-CH01) isolated from the Cheffia Dam in Algeria. The presence of microcystin synthetase genes (mcyA, $-B$, and $-C)$ in isolated colonies of this morphospecies, and the fact that serine/threonine phosphatase (PP2A) was inhibited by its crude extract indicated that this morphospecies was microcystin-producer. The morphological features of this unusual morphospecies were very different from any of those described in the literature of all known species of Microcystis. The phylogenic tree based on 16S rDNA sequences shows that this morphospecies is indistinguishable from the reference strain Microcystis aeruginosa PCC 7806 and from many other known Microcystis species and, therefore, this tree did not necessarily correlate to the distinctions between morphospecies. However, phylogenetic analysis based on the 16S-23S rRNA spacer region could be an effective way to assign this unusual morphospecies MCYS-CHO1 to the Asian species Microcystis novacekii. Comparison of the ITS sequence of this morphospecies with sequences available in the GenBank database showed that some highly conserved genotypes are found throughout the world.
\end{abstract}

Key words: Cyanobacteria, $16 \mathrm{~S}$ rRNA, ITS, Microcystins

\section{INTRODUCTION}

Blooms of toxic cyanobacteria constitute a threat to the safety and ecological quality of surface waters worldwide. The genus Microcystis constitutes one of the most widely distributed toxic bloom-forming genera of cyanobacteria (Sivonen \& Jones 1999). Within the North-African basin, several studies in Morocco (Oudra et al. 2001; Sabour et al. 2002), Algeria (Nasri et al. 2004), and Tunisia (El Herry et al. 2008), neighboring countries with similar climatic conditions, have shown that natural cyanobacterial blooms containing microcystins are dominated by the genus Microcystis. In Egypt, however, microcystins have been isolated and characterized from both Microcystis aeruginosa (AbdelRahman et al. 1993; Mohamed et al. 2003) and Oscillatoria tenuis (Brittain et al. 2000). The group of toxin produced by Microcystis is the microcystin hepatotoxins, a cyclic heptapeptides which are formed non-ribosomally by peptide and polyketide synthetases (Dittmann et al. 1997; Tillett et al. 2001). They have been implicated in deaths due to microcystin-induced liver failure in domestic and wild animals (Codd et al. 2005), as well as in human illness (Kuiper-Goodman et al. 1999, Codd et al. 2005) and, as a result of exposure through hemodialysis, even in human death (Jochimsen et al. 1998; Pourria et al. 1998; Carmichael et al. 2001).

All species within the genus Microcystis have been reported to include microcystin-producing strains as well as strains that do not synthesize microcystin. Characterization of Microcystis species using conventional methods based on morphological features is very difficult, and only limited differentiation is possible below genus level. The genus Microcystis is clearly delimited at the genus level by molecular sequencing ( $\mathrm{Li}$ et al. 1998) but in the field it occurs in the form of characteristic colonies that can be classified as different morphological types (morphotypes), each of which is equivalent to a species (morphospecies) (Komárek \& Anagnostidis 1999). Microcystis colonies differ in shape and size, but also in the appearance of their mucilage (Watanabe 1996). However, the validity of the morphological taxonomy of these species has always been questioned. Several attempts have been made to define taxonomic criteria, other than morphological ones, based specially on 16S rDNA sequence comparisons (Neilan et al. 1997; Otsuka et al. 1998) for the different Microcystis species. Given that the taxonomic resolution offered by $16 \mathrm{~S}$ rRNA genes is insufficient to distinguish between closely related organisms, research has increasingly focused on the rRNA $16 \mathrm{~S}$ to $23 \mathrm{~S}$ internal 
transcribed spacer (rRNA-ITS). Restriction enzyme digestion of rRNA-ITS has been used to resolve closelyrelated cyanobacterial strains (Lu et al. 1997; Neilan et al. 1997; Laloui et al. 2002), and direct sequencing has been used to study subgeneric phylogenetic relationships in genera such as Microcystis (Otsuka et al. 1999). Furthermore, analysis of the length polymorphism and restriction fragment length polymorphism (RFLP) of the amplified rRNA-ITS region has generally made it possible to assign the cyanobacteria tested at genus and species level (Boyer et al. 2001). In fact, the high interspecific variability reported for this rRNA spacer makes it a promising candidate for RFLP. In this paper, we present the toxicological potential, morphological characteristics and phylogenetic analysis based on the $16 \mathrm{~S}$ rDNA sequence of unusual non-axenic Microcystis morphospecies (MCYS-CH01) collected from the Cheffia Dam in Algeria. Furthermore, the 16S-23S rRNA ITS of this morphospecies was sequenced, and compared with some entire ITS sequences of different species of Microcystis available in GenBank. For the purposes of comparison, the axenic strain $M$. aeruginosa PCC 7806 was also included in this study as a reference strain.

\section{MATERIALS AND METHODS}

\subsection{Study sites}

The Cheffia Dam is located in the El Taref Wilaya in the north-eastern Algeria with the coordinates of $36^{\circ} 07^{\prime} \mathrm{N}$ and $8^{\circ} 03^{\prime} \mathrm{E}$, it covers 1000 hectares and has a maximum depth of $30 \mathrm{~m}$, and it provides drinking water for the Wilaya of Annaba and the surrounding area (population 1 million).

\subsection{Sampling and morphological characterization of Microcystis morphospecies}

Sampling for colony isolation and morphological characterization was carried in the autumn of 2005 , and identified dominance of the genus Microcystis, in the Cheffia Dam by means of hauls with plankton nets (20$\mu \mathrm{m}$ mesh size). Aliquots of the concentrated net samples were fixed with formaldehyde ( $5 \%$ f.c.) solution, and stored in the dark before being used for detailed determinations of the cell size, colony form, and sheath characteristics of the Microcystis morphospecies MCYS$\mathrm{CH} 01$. The cell diameter was determined for 50 cells (10 cells from 5 different colonies). The remaining fresh phytoplankton sample was used for colony isolation as described below.

\subsection{Isolation and toxic potential of the Microcystis morphospecies MCYS-CHO1}

For isolation of colony of the Microcystis morphospecies MCYS-CH01, fresh phytoplankton samples were diluted in sterilized Milli-Q water and individual colonies picked out by means of tiny Pasteur pipettes under binocular microscopes. Isolated colonies were then washed by transferring them into several drops of sterilized Milli-Q water until all other organisms had been removed. It was not possible to remove epiphytic cyanobacteria and algae stuck in the mucilage of Microcystis sp., but the absence of other cyanobacteria was checked by visual inspection under the microscope. Each series of ten isolated colonies were pooled separately in a sterilized Eppendorf tube $(1.5 \mathrm{~mL})$ and then lyophilized. Aliquots were then used to determine the toxic potential by the PP2A inhibition assay and mcy genes cluster amplification. For the PP2A inhibition assay, lyophilized materials of the morphospecies MCYS-CH01 and the reference strain Microcystis aeruginosa PCC 7806 were extracted with $100 \mu \mathrm{L}$ aqueous methanol $(75 \%, \mathrm{v} / \mathrm{v})$, and then centrifuged at $5000 \mathrm{~g}$ for $10 \mathrm{~min}$. An aliquot from each supernatant was then analyzed by the PP2A inhibition assay as described in Bouaïcha et al. (2001).

\subsection{PCR amplification of the microcystin biosynthesis genes mсу $A, \operatorname{mcy} B$ and mcy $C$}

PCR amplifications of $m c y \mathrm{~A}, m c y \mathrm{~B}$ and $m c y \mathrm{C}$, which are indicative of the presence of the microcystin biosynthesis genes cluster (Dittmann \& Börner 2005), were performed by isolating the DNA directly from cell lysates obtained after five alternating cycles of freezing in liquid nitrogen and thawing at $55^{\circ} \mathrm{C}$ (Iteman et al. 2000). The primers listed in table 1 were used to amplify the NMT domain of the microcystin synthetase genes $m c y \mathrm{~A}, m c y \mathrm{~B}$, and $m c y \mathrm{C}$. The PCR mixture contained $2.5 \mu \mathrm{L}$ of $10 \times$ PCR Buffer, $0.75 \mu \mathrm{L}$ of $50 \mathrm{mM}$ $\mathrm{MgCl}_{2}, 0.05 \mu \mathrm{L}$ of a $100 \mathrm{mM}$ concentration of each deoxynucleoside triphosphate, $0.5 \mu \mathrm{L}$ of $10 \mathrm{pmol}_{\mu} \mathrm{L}^{-1}$ of the NMT primers, $10 \mu \mathrm{L}$ lysate cells, $0.5 \mu \mathrm{L}$ of a $5 \mathrm{U}$ $\mu \mathrm{L}^{-1}$ Taq DNA polymerase, and water to give a final volume of $25 \mu \mathrm{L}$. All PCR reagents were purchased from Invitrogen, France. The reaction mixtures were incubated in a Hybaid PCRExpress Thermal Cycler using the following program. After an initial cycle consisting of $5 \mathrm{~min}$ at $94{ }^{\circ} \mathrm{C}$, and then 35 cycles of $95^{\circ} \mathrm{C}$ for $60 \mathrm{~s}, 52{ }^{\circ} \mathrm{C}$ for $30 \mathrm{~s}$ and $72{ }^{\circ} \mathrm{C}$ for $60 \mathrm{~s}$, the reaction was terminated by a cycle of $7 \mathrm{~min}$ at $72{ }^{\circ} \mathrm{C}$ for $m c y \mathrm{~B}$ and $m c y \mathrm{C}$. The $m c y \mathrm{~A}$ gene PCR amplification involved an initial cycle of $7 \mathrm{~min}$ at $94{ }^{\circ} \mathrm{C}$, followed by 30 cycles with $94{ }^{\circ} \mathrm{C}$ for $10 \mathrm{~s}, 60^{\circ} \mathrm{C}$ for $20 \mathrm{~s}$ and $72{ }^{\circ} \mathrm{C}$ for $60 \mathrm{~s}$, terminating with a cycle at $72{ }^{\circ} \mathrm{C}$ for $7 \mathrm{~min}$. The reaction mixtures were stored at $4{ }^{\circ} \mathrm{C}$. The PCR products were then analyzed by electrophoresis on $1.5 \%$ agarose gel in 1× TBE (Tris-borate-EDTA) buffer, stained with SYBR SafeTM DNA gel stain (Invitrogen, France), and photographed under UV light. The length of DNA fragments was estimated by comparison with a $1 \mathrm{~Kb}$ plus DNA ladder (Invitrogen, France). 
Tab. 1. Primers used in amplifying and sequencing of the 16S rRNA and the 16S-23S rRNA ITS regions and detecting mcyA, $\mathrm{B}$, and -C genes of the Microcystis morphospecies (MCYS-CH01) isolated from the Cheffia dam (Algeria) and the reference strain M. aeruginosa PCC 7806.

${ }^{\mathrm{a}} \mathrm{F}$ designates forward primer, $\mathrm{R}$ designates reverse primer. *Primer 322 initiates amplification at a region near the end of the $16 \mathrm{~S}$ rDNA on the RNA-like strand (positions 1338-1354 in Synechocystis PCC 6803; Escherichia coli numbering 1391-1407), and primer 340 is complementary to a region on the opposite strand at the beginning of the 23S rDNA (positions 26-45 in both Synechocystis PCC 6803 ; E. coli).

\begin{tabular}{|c|c|c|c|c|}
\hline Genes & Primers & Sequences $\left(5^{\prime}-3^{\prime}\right)$ & Amplified fragments (bp) & References \\
\hline$m c y \mathrm{~A}$ & $\mathrm{MSF}^{\mathrm{a}} \mathrm{MSR}^{\mathrm{a}}$ & $\begin{array}{l}\text { ATCCAGCAGTTGAGCAAGC } \\
\text { TGCAGATAACTCCGCAGTTG }\end{array}$ & 1300 & Tillett et al. 2001 \\
\hline$m c y \mathrm{~B}$ & $2156-\mathrm{F}^{\mathrm{a}} 3111-\mathrm{R}^{\mathrm{a}}$ & $\begin{array}{c}\text { ATCACTTCAATCTAACGACT } \\
\text { AGTTGCTGCTGTAAGAAA }\end{array}$ & 955 & Mikalsen et al. 2003 \\
\hline$m c y \mathrm{C}$ & $\mathrm{PSCF}^{\mathrm{a}}{ }^{\mathrm{PSCR}} 1^{\mathrm{a}}$ & $\begin{array}{c}\text { GCAACATCCCAAGAGCAAAG } \\
\text { CCGACAACATCACAAAGGC }\end{array}$ & 674 & Ouahid et al. 2005 \\
\hline 16S rDNA & $27 \mathrm{~F} 1^{\mathrm{a}} 1494 \mathrm{Rc}^{\mathrm{a}}$ & $\begin{array}{l}\text { AGAGTTTGATCCTGGCTCAG } \\
\text { TACGGCTACCTTGTTACGAC }\end{array}$ & 1467 & Neilan et al. 1997 \\
\hline ITS & $322 \mathrm{Fa} 340 \mathrm{R}^{\mathrm{a}}$ & $\begin{array}{c}\text { TGTACACACCGCCCGTC } \\
\text { CTCTGTGTGCCTAGGTATCC }\end{array}$ & about $560^{*}$ & Iteman et al. 2000 \\
\hline
\end{tabular}

\subsection{PCR amplification and sequencing of the $16 \mathrm{~S}$ rDNA regions}

PCR amplifications of the $16 \mathrm{~S}$ rDNA regions of the morphosepcies MCYS-CH01 and the reference strain PCC 7806 were performed directly with $5 \mu \mathrm{L}$ lysate cells as described above. A set of primers $(27 \mathrm{~F} 1$ and $1494 \mathrm{Rc}$ ) was used, and the sequences of each primer are indicated in table 1 . Incubation of the reactions was performed in a Hybaid PCRExpress Thermal Cycler using the following program. After an initial cycle consisting of 5 min at $94{ }^{\circ} \mathrm{C}, 35$ amplification cycles were started $\left(30 \mathrm{~s}\right.$ at $94{ }^{\circ} \mathrm{C}, 30 \mathrm{~s}$ at $50{ }^{\circ} \mathrm{C}$ and $1 \mathrm{~min}$ at $70{ }^{\circ} \mathrm{C}$ ). The reaction was terminated by a cycle of $3 \mathrm{~min}$ at $72{ }^{\circ} \mathrm{C}$. The PCR products were then analyzed by electrophoresis as explained before.

In order to obtain enough DNA quantity, the PCR products of three independent reactions were pooled and purified using the ChargeSwitch ${ }^{\circledR}$ PCR Clean-Up kit (Invitrogen, France) to remove amplification reaction components, including unincorporated primers and nucleotides, and then sequenced using the same set of primers as for amplification (27F1 and 1494Rc) by Plate-forme Génotypage des Pathogènes et Santé Publique (Institut Pasteur, Paris, France). DNA was sequenced with the big dye-terminator cycle sequencing kit using an ABI PRISM 3730XL DNA sequencer (Applied Biosystems). The 16S rDNA sequences of the morphospecies MCYS-CH01 and the reference strain PCC 7806 were aligned using Genedoc v2.6.0002 software (www.psc.edu/biomed/genedoc), with a representative data set of sequences of Microcystis species available in GenBank. Relationships between the strains were inferred using the maximum likelihood method (Olsen et al. 1994). The phylogenetic tree was midpoint rooted, using the strain Synechococcus elongatus PCC 7942 (accession number AF132930) as the out-group. The statistical significance of the branches was estimated by analysis of the tree programs, involving the generation of 1000 trees.

\subsection{PCR amplification and sequencing of the ITS regions}

PCR amplifications of the ITS regions were performed directly using $5 \mu \mathrm{L}$ lysate cells as described above. A set of primers (322 and 340) was used to amplify specifically the part of the rRNA operon containing the ITS region. The sequences of each primer are indicated in table 1. After an initial cycle consisting of $5 \mathrm{~min}$ at $94{ }^{\circ} \mathrm{C}, 30$ cycles of amplification were started $\left(0.5 \mathrm{~min}\right.$ at $94{ }^{\circ} \mathrm{C}, 0.5 \mathrm{~min}$ at $50^{\circ} \mathrm{C}$ and $1 \mathrm{~min}$ at $70{ }^{\circ} \mathrm{C}$ ). The termination cycle consisted of $3 \mathrm{~min}$ at 72 ${ }^{\circ} \mathrm{C}$. The PCR products were then analyzed by electrophoresis as explained before.

In order to obtain enough DNA quantity, the PCR products from five independent reactions of each morphospecies were pooled and purified using the ChargeSwitch ${ }^{\circledR}$ PCR Clean-Up kit (Invitrogen, France), and then sequenced using the same set of primers as for amplification (322 and 340) by GenoScreen (Campus Pasteur, Lille, France). DNA was sequenced with the Applied Biosystems ready reaction kit using an ABI PRISM 3730XL DNA sequencer (Applied Biosystems). Methods used for DNA alignment and phylogenetic analyses of the 16S-23S ITS region were the same as those described above for the 16S rDNA sequence.

\subsection{Nucleotide sequence accession numbers}

The 16S and ITS sequences of the unusual morphospecies of Microcystis MCYS-CH01 reported in this paper were deposited in the GenBank database under the following accession numbers. The $16 \mathrm{~S}$ sequence: EU541973, and the ITS sequence: EU541975.

\section{RESULTS}

\subsection{Morphological characteristics and toxigenic potential of the morphospecies MCYS-CHOI}

The dominant morphospecies (MCYS-CH01) observed in the autumn in the samples from the Cheffia 


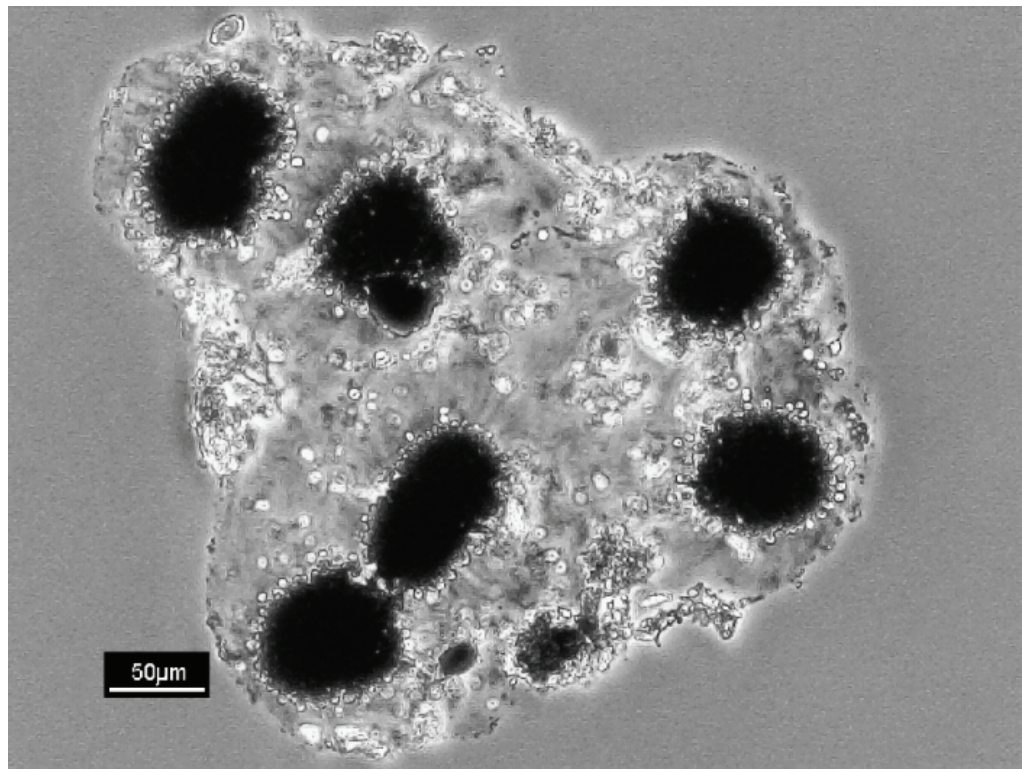

Fig. 1. Light micrograph showing morphological characteristics of colony of the morphospecies Microcystis sp. (MCYS-CH01) isolated from the Cheffia Dam (Algeria).

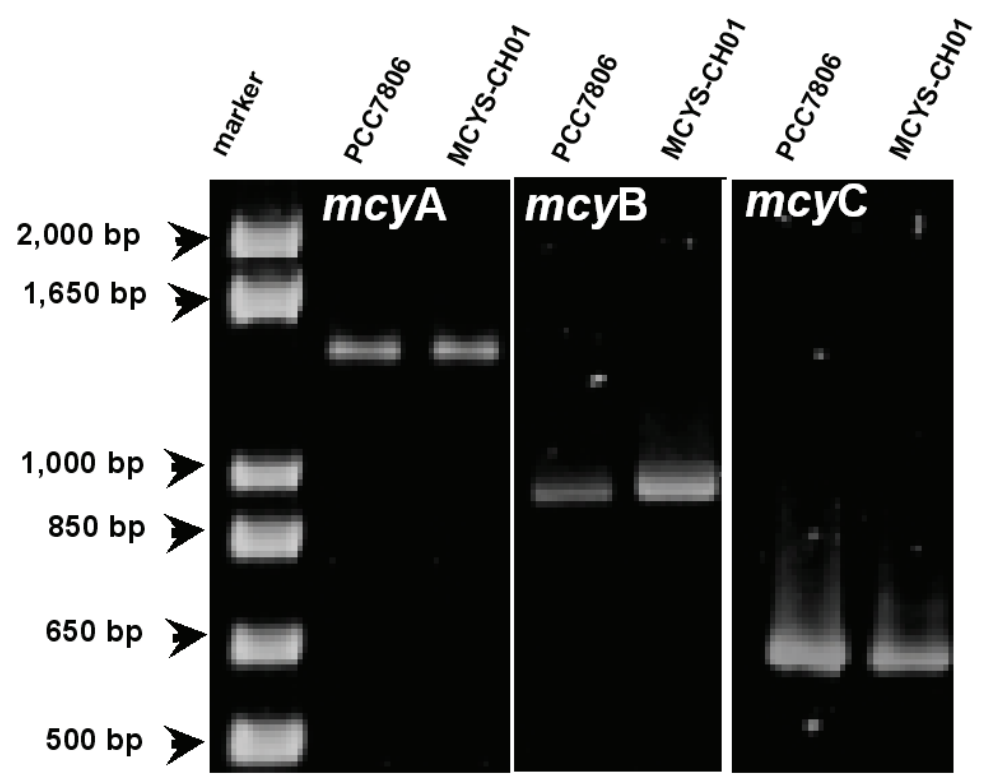

Fig. 2. Gel electrophoresis of PCR products of the morphospecies (MCYS- CH01) and the reference strain M. aeruginosa PCC 7806 of the genus Microcystis for mcyA, -B, and -C genes using primer sets MSF-MSR, 2156F-3111R, and PSCF1-PSCR1, respectively.

Dam (Algeria) was isolated, and its morphological characteristics were described. As shown in figure 1 this morphospecies displayed large colonies, up to the macroscopic level. These colonies were irregular in outline, and were composed of small subcolonies each containing densely packed cells. The mucilage was colorless, very thick, and clearly extended more than $50 \mu \mathrm{m}$ beyond the outline of the cell cluster. The cells were spherical and small (diameter 3-4 $\mu \mathrm{m}$ ), and contained only a few gas vesicles. The morphological features of this unusual morphospecies were different from any of those described in the literature of all known species of Microcystis, and may constitute a new species. The
PP2A inhibition assay showed that crude methanol extracts of the morphospecies MCYS-CH01 and of the reference strain M. aeruginosa PCC 7806 all inhibited the activity of the PP2A enzyme. Furthermore, as shown in figure 2 the presence of microcystin synthetase genes $m c y \mathrm{~A},-\mathrm{B}$, and $-\mathrm{C}$ indicated that these two morphospecies are microcystin-producers.

\subsection{Comparison of $16 S$ rRNA gene sequences for different Microcystis morphospecies}

A set of 2 primers 27F1 and 1494Rc, was used for the PCR amplification of $16 \mathrm{~S}$ rRNA genes from the axenic reference strain PCC 7806 isolated from the Bra- 


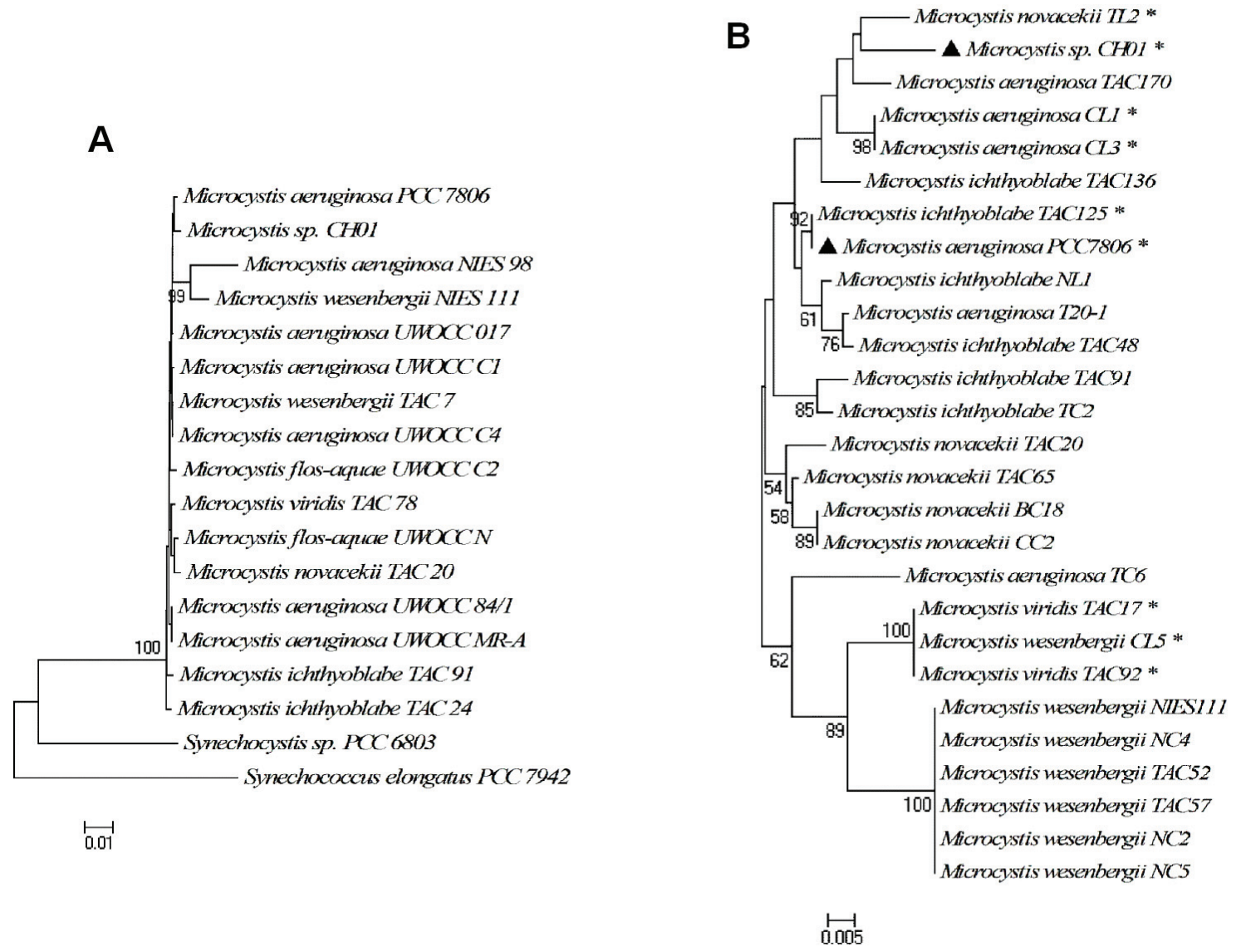

Fig. 3. Phylogenetic trees based on (A) 16S rDNA sequences showing the relationships between cyanobacteria strains of Microcystis. Outgroup Synechococcus elongatus PCC 7942 and Synechocystis sp. PCC 6803. An alignment of 1400 nucleotides after excluding positions with gaps was used. Scale bar $=1$ base substitution per 100 nucleotide positions. Local bootstrap probabilities (for branches except those within the Microcystis cluster) are indicated at nodes. Accession numbers in the GenBank databases are Microcystis aeruginosa D89032, AF139316, AF139315, AF139294, AF139301, AF139320, AF139299, M. novacekii AB012336, M. wesenbergii D89034, AB035553, M. ichthyoblabe AB035550, AB012339, and M. viridis AB012331, and Microcystis sp. (MCYSCH01) EU541973 and on (B) 16S-23S rRNA sequences showing the relationships between the morphospecies Microcystis sp. (MCYS-CH01) isolated from Cheffia Dam (Algeria) and the toxic reference strain M. aeruginosa PCC 7806 and some Asian Microcystis strains sequenced by Otsuka et al. (1999). Bootstrap probabilities ( $>50 \%)$ are indicated at the nodes. Strains asterisked are microcystin-producers. Black triangle indicates strains sequenced in this study. Accession numbers in the GenBank databases of the morphoespecies Microcystis sp. (MCYS-CH01) EU541975 and of the different Asian strain sequenced by Otsuka et al. (1999) are given in table 2 .

akman reservoir (Netherlands), and from the non-axenic Microcystis morphospecies (MCYS-CH01) isolated from the Cheffia Dam (Algeria). The specifically designed primers (27F1 and 1494Rc) enabled us to sequence both strands of 16S rDNA with overlaps. Complete sequences for both strands of the 16S rDNA were generated for the region extending from position 27 to position 1494 (E. coli numbering) for the two morphospecies tested. The assembled sequences were analyzed using the NCBI BLASTN 2.1.3 (http:///www.ncbi.nlm.nih.gov/blast/) program to align them with database sequences, and to check that the sequences generated were cyanobacterial in origin. The 16S rDNA sequences identified were compared to each other and to those of previously published almost-complete 16S rDNA sequences for Microcystis species and related organisms available in GenBank. After ambigu- ous characteristics had been removed from the alignment, 1,400 nucleotide positions were used for successive phylogenetic analyses. The morphospecies MCYS$\mathrm{CHO} 1$ and the reference strain tested, and some previously published complete $16 \mathrm{~S}$ rDNA sequences for some Microcystis species, showed high DNA sequence similarity exceeding 99\%. Constructed phylogenetic neighbor-joining trees (Fig. 3A) revealed that all these Microcystis strains formed a clearly-defined cluster with no clear divisions between them.

\section{3. rRNA ITS gene sequence and phylogenetic analysis of the morphospecies MCYS-CHO1}

To elucidate phylogenetic difference between morphospecies MCYS-CH01, reference strain PCC 7806, and various Microcystis morphospecies described in the literature, DNA fragments covering the ITS of the refer- 


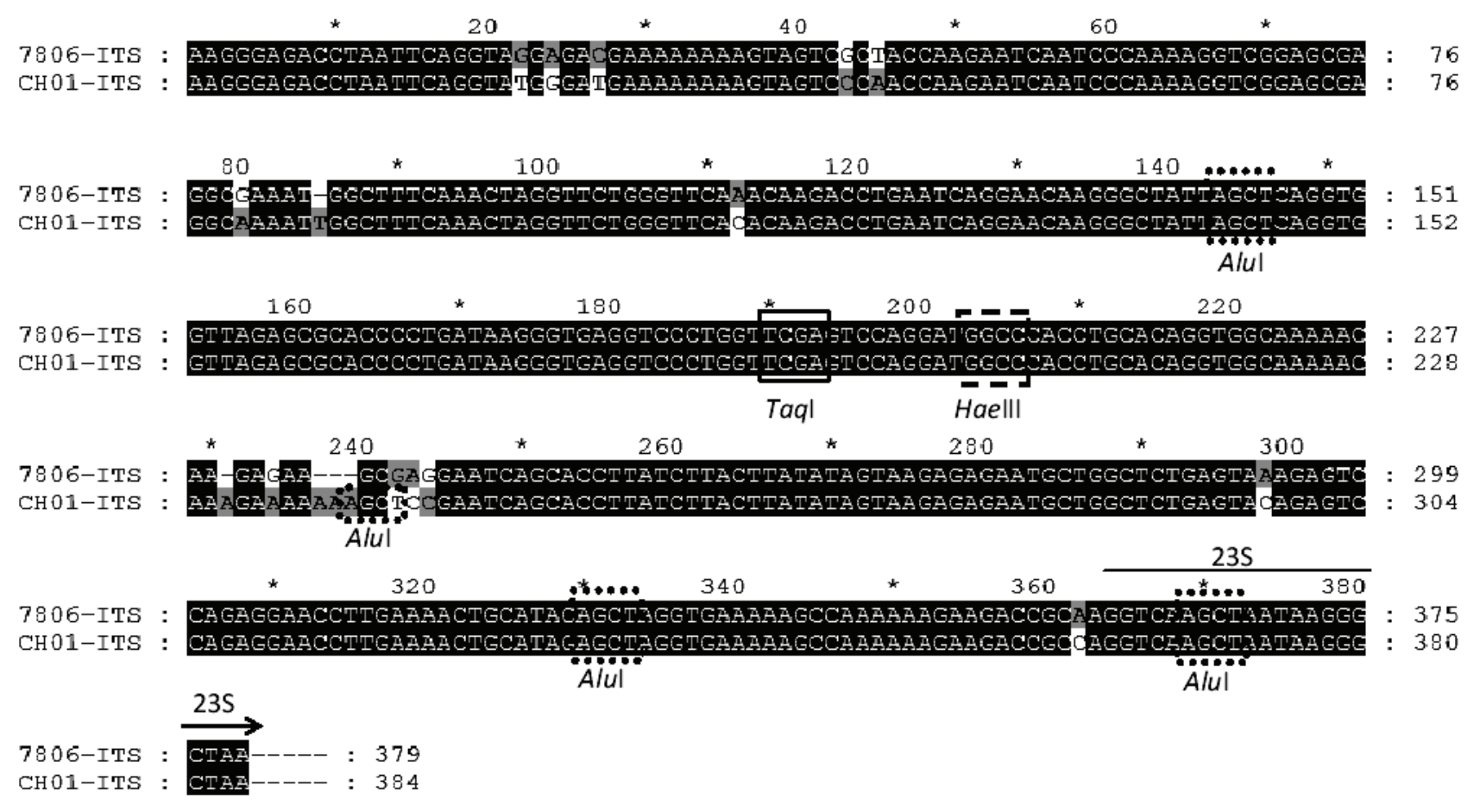

Fig. 4. Alignment of the nucleotide sequences of the ITS regions of the morphospecies Microcystis sp. (MCYS-CH01) isolated from Cheffia Dam (Algeria) and the reference strain M. aeruginosa PCC 7806. Rectangles indicate the cleavage site of the restriction enzymes (dotted line) AluI, (continuous line) TaqI, and (broken line) HaeIII. The arrow above the sequence of the ITS of the reference strain PCC 7806 indicates the 5' beginning of the 23S rRNA gene.

ence strain and of morphospecies MCYS-CH01 were sequenced and compared to 26 Asian Microcystis species sequenced by Otsuka et al. (1999). The length of the entire ITS sequences of the reference strain PCC 7806 and of morphospecies MCYST-CH01 are 358 and $363 \mathrm{bp}$, respectively. This length range is in overall agreement with the band (about $560 \mathrm{bp}$ ) observed by gel electrophoresis that, for the set of primers used, should have been $200 \mathrm{bp}$ longer. The conserved domains (D1, D1', D2, D3, D4, D5 and box 5) and one tRNA gene, tRNAIle described by Iteman et al. (2000), were found in both these sequences. Recognition sites for each of the restriction enzymes TaqI and HaeIII were observed at positions 190 and 202, respectively, in the sequences (Fig. 4). However, three cleavage sites for the restriction enzyme AluI were observed in the ITS sequence of morphospecies MCYS-CH01, but only two in that of reference strain PCC 7806 (Fig. 4). This was confirmed by the point mutation (position 238) at the cleavage site of restriction enzyme AluI in the gene sequence of reference strain PCC 7806 (Fig. 4). In addition, one cleavage site of AluI was also observed at the beginning of 23S rDNA, and at the same position for both the PCC 7806 and MCYS-CH01 morphospecies (Fig. 4).

A phylogenetic tree was constructed based on the alignment of the rDNA ITS sequences of morphospecies MCYS-CH01, reference strain PCC 7806 and 26 Asian Microcystis species sequenced by Otsuka et al.
(1999). The similarity of the ITS sequence of morphospecies MCYS-CH01 was still high (92-98\% sequence identity) compared to the other strains (Tab. 2). The distribution of the 28 sequences in a phylogenetic tree (Fig. 3B) did not reveal any obvious segregation between morphospecies MCYS-CH01, isolated from the Cheffia Dam (Algeria), reference strain PCC 7806 isolated from the Braakman reservoir (Netherlands), and the 26 sequences obtained by Otsuka et al. (1999) from Microcystis species isolated from Asian lakes and added to our analysis. Consequently, morphospecies MCYS-CH01 and reference strain PCC 7806 sequenced in this study are included in cluster I described by Otsuka et al. (2000) for some Asian strains belonging to all $M$. novacekii and $M$. ichthyoblabe strains, and most $M$. aeruginosa strains.

\section{DISCUSSION}

The genus Microcystis is usually linked to hepatotoxic blooms world-wide (Sivonen \& Jones 1999). According to Komárek \& Anagnostidis (1999), Microcystis is characterized by having gas vesicles, a coccoid cell shape, a tendency to form aggregates or colonies, and an amorphous mucilage or a sheath. Based on these criteria, ten species have been distinguished in Europe: Microcystis aeruginosa (Kützing) Kützing, M. viridis (A. Braun in Rabenhorst) Lemmermann, M. wesenbergii (Komárek) Komárek in Kondratieva, M. novacekii 
Tab. 2. Similarities between the 16S-23S rRNA ITS sequence of the morphospecies Microcystis sp. (MCYS-CH01) isolated from Cheffia dam and the ITS sequences of the reference strain M. aeruginosa PCC 7806 and some Asian Microcystis strains sequenced by Otsuka et al. (1999). *Strain marked with "+" produces microcystin(s) and one with "-" does not.

\begin{tabular}{|c|c|c|c|c|c|}
\hline Morphospecies & Reference strain & Accession number & Source of isolate & Microcystin* & $\%$ of sequence identity \\
\hline Microcystis novacekii & TL2 & AB015380 & Thaïland & + & 98 \\
\hline Microcystis ichthyoblabe & $\mathrm{TC} 2$ & AB015372 & Thaïland & - & 98 \\
\hline Microcystis aeruginosa & TAC170 & $\mathrm{AB} 015365$ & Japan & Unknown & 98 \\
\hline Microcystis ichthyoblabe & NL1 & $\mathrm{AB} 015371$ & Japan & - & 97.6 \\
\hline Microcystis ichthyoblabe & TAC125 & AB015368 & Japan & + & 97.6 \\
\hline Microcystis aeruginosa & PCC 7806 & - & The Netherlands & + & 97.3 \\
\hline Microcystis novacekii & TAC65 & $\mathrm{AB} 015375$ & Japan & - & 97.3 \\
\hline Microcystis aeruginosa & T20-1 & AB015384 & Thaïland & - & 97 \\
\hline Microcystis ichthyoblabe & TAC48 & AB015366 & Japan & - & 97 \\
\hline Microcystis novacekii & $\mathrm{CC} 2$ & AB015378 & China & - & 97 \\
\hline Microcystis novacekii & BC18 & AB015377 & United Kingdom & - & 97 \\
\hline Microcystis novacekii & TAC20 & AB015374 & Japan & - & 96 \\
\hline Microcystis aeruginosa & CL1 & AB015381 & China & + & 96 \\
\hline Microcystis aeruginosa & CL3 & AB015382 & China & + & 96 \\
\hline Microcystis wesenbergii & CL5 & AB015392 & China & + & 95 \\
\hline Microcystis viridis & TAC92 & AB015402 & Japan & + & 95 \\
\hline Microcystis ichthyoblabe & TAC91 & AB015367 & Japan & - & 96 \\
\hline Microcystis viridis & TAC17 & AB015398 & Japan & + & 95 \\
\hline Microcystis ichthyoblabe & TAC136 & AB015369 & Japan & - & 95 \\
\hline Microcystis wesenbergii & NIES111 & AB015388 & Japan & - & 94 \\
\hline Microcystis wesenbergii & TAC52 & AB015390 & Japan & - & 94 \\
\hline Microcystis wesenbergii & TAC57 & AB015391 & Japan & - & 94 \\
\hline Microcystis wesenbergii & $\mathrm{NC} 4$ & AB015396 & Japan & - & 93 \\
\hline Microcystis wesenbergii & $\mathrm{NC} 2$ & AB015394 & Japan & - & 93 \\
\hline Microcystis wesenbergii & $\mathrm{NC5}$ & AB015397 & Japan & - & 93 \\
\hline Microcystis aeruginosa & TC6 & AB015385 & Thaïland & - & 92 \\
\hline
\end{tabular}

(Komárek) Compère, M. ichthyoblabe (Kützing), $M$. flos-aquae (Wittrock) Kirchner. M. natans (Lemmermann) ex Skuja, M. firma (Kützing) Schmidle, $M$. smithii (Kützing et Anagnostidis), and M. botrys (Teiling). Many other species have been also characterized outside Europe (Komárek \& Anagnostidis 1999). In this study, unusual morphospecies, Microcystis sp. (MCYSCH01), has been identified in Algeria in the Cheffia Dam (Fig. 1). Colonies of this morphospecies are lenticular or almost spherical, irregularly spherical or slightly elongate or with wavy outline, compact, with packed cells, without holes and not lobate, in old stages composed of several clustered subcolonies, with a large number of densely aggregated cells. Mucilage was colorless, very thick, delimited at the margin, not diffluent; the wide margins around central cell clusters reach to 50 $\mu \mathrm{m}$ width. The cells were spherical and small (diameter 3-4 $\mu \mathrm{m}$ ), and contained only a few gas vesicles.

Three species, Microcystis aeruginosa, M. wesenbergii and $M$. ichthyoblabe are often found in North African freshwater bodies (Oudra et al. 2001, Oudra et al. 2002, Nasri et al. 2004), however, this unusual Microcystis morphospecies was reported for the first time by Nasri et al. (2007) as the dominant Microcystis sp. forming bloom in the Cheffia Dam (Algeria). The presence of microcystin synthetase genes $m c y \mathrm{~A}$, -B, and $-\mathrm{C}$ in colonies of this morphospecies, and the fact that serine/threonine phosphatase (PP2A) was inhibited by its crude methanol extract indicated that it was microcystin-producer.

In contrast to its morphological classification, analysis of the $16 \mathrm{~S}$ rDNA sequence of this non-axenic morphospecies revealed a high degree of similarity $(>99 \%$ sequence identity) between them and the reference strain PCC 7806, and previously published almost complete 16S rDNA sequences for known Microcystis species (Fig. 3A). Several previous studies based on $16 \mathrm{~S}$ rDNA have shown that different species of Microcystis can be clustered together (Neilan et al. 1997; Lyra et al. 2001). Otsuka et al. (1998) found that five Microcystis species: Microcystis aeruginosa, M. ichthyoblabe, $M$. wesenbergii, $M$. viridis, and $M$. novacekii, were so closely related in terms of $16 \mathrm{~S}$ rDNA sequence that they can be grouped as a single species, and concluded that the $16 \mathrm{~S}$ rDNA sequence is insufficiently variable to be used for phylogenetic analysis of these organisms at species level. Moreover, Neilan et al. (1997) have reported that minor and variable morphometric parameters may have led to the identification of $M$. wesenbergi and $M$. viridis, although it is difficult to justify their separation from $M$. aeruginosa on the basis of the results of $16 \mathrm{~S}$ rRNA gene analyses. The difference in resolution from 16S rRNA in Microcystis matches the reported average sequence diversity of less than $1 \%$ in this gene (Otsuka et al. 1998, Boyer et al. 2001). Knowing that the internal transcribed spacer (ITS) 
region between $16 \mathrm{~S}$ and 23S rRNA genes is less conserved than the 16S rRNA gene in cyanobacteria (Neilan et al. 1997, Otsuka et al. 1999), we investigated the possible use of this domain for genotyping the unusual non-axenic morphospecies MCYS-CH01. To provide a comparison, the axenic strain Microcystis aeruginosa PCC 7806 was also included in this study as a reference strain. We found that reference strain PCC 7806 and morphospecies MCYS-CH01 displayed similar ribotypes, with an ITS size of about 360 bp (PCR product of about $560 \mathrm{bp}$ ). This is consistent with results reported in several studies (Lu et al. 1997; Otsuka et al. 1999; Janse et al. 2004; Humbert et al. 2005), where the size of ITS for some Microcystis species ranged from 320 to 365 bp.

In order to compare the genetic diversity of the unusual morphospecies MCYS-CH01, isolated from the Cheffia Dam (Algeria), to that of morphospecies isolated from other water-bodies separated by geographic distance as well as having different physical and chemical parameters, 26 of the 47 sequences obtained by Otsuka et al. (1999) from different Microcystis morphospecies isolated from Asian lakes were included in the analysis. Although the variation in the sequence of 16S-23S ITS regions of different Microcystis morphospecies was found to be more variable (92-98\% sequence identity) than the corresponding $16 \mathrm{~S}$ rDNA sequences ( $>99 \%$ sequence identity), the ITS sequences of the different Microcystis morphospecies were homogenous regardless of their geographical origin. Here we show that morphospecies MCYS-CH01 had a very similar $16 \mathrm{~S}-23 \mathrm{~S}$ ITS sequence $(98 \%$ sequence identity) to that of the toxic strains $M$. novacekii T20-3 and TL2 described by Otsuka et al. (1999), and it was therefore assigned to Microcystis novacekii. The high degree of relatedness between these strains is entirely consistent with their common phenotypic characters: colonies are small and firm, not lobular, composed of tightly aggregated cells, and are surrounded by a thick gelatinous substance (Otsuka et al. 2000). In contrast, the non-toxic strains $M$. novacekii TAC65, CC2, BC18, and TAC20, share only $96-97.3 \%$ sequence identity (Tab. 2). Otsuka et al. (1999) reported that cluster I, which includes all the $M$. novacekii and M. ichthyoblabe strains and most $M$. aeruginosa strains, included both toxic and non-toxic strains. Watanabe (1996) used the term 'M. aeruginosa complex' for these last three morphospecies, since their properties are obscure. It has previously been demonstrated that there is no clear relationship between rRNA gene phylogeny and microcystin production in the genus Microcystis (Tillett et al. 2001). Furthermore, since microcystins can also be synthesized by other cyanobacteria genera (e.g., Anabaena spp., Nostoc spp., Oscillatoria spp., and Planktothrix spp.), the production of these toxins must have originated in a common ancestral cyanobacterium, and the observed heterogeneous distribution of toxic and non-toxic strains may result from gene deletions occurring a number of times during evolution.

\section{CONCLUSION}

In conclusion, the presented morphological characteristics such as the presence of very thick and clearly extended mucilage and specially the molecular results based on the analysis of the 16S-23S rRNA spacer region, suggested that the unusual Microcystis morphospecies MCYS-CH01 isolated from the Cheffia Dam (Algeria) should be assigned to Microcystis novacekii. The comparison of the ITS sequence of this morphospecies with those of different species of Microcystis available in the GenBank database showed that some highly conserved genotypes are found throughout the world.

\section{ACKNOWLEDGMENTS}

We are grateful to Dr I. Iteman (Plate-forme Génotypage des Pathogènes et Santé Publique, Institut Pasteur, Paris, France) for the $16 \mathrm{~S}$ rDNA sequencing of the Microcystis morphospecies. This work was supported by grant from the Ministère de l'Enseignement Supérieur de la Recherche et de la Technologie, France. S. El Herry was a recipient of a fellowship from the Embassy of France in Tunisia, Service of co-operation and cultural action. We are grateful to the critical comments of the anonymous referees. The manuscript has been checked by a native speaker of English Monika Ghosh.

\section{REFERENCES}

Abdel-Rahman, S., Y.M. El-Ayouty \& H.A. Kamael. 1993. Characterization of heptapeptide toxins extracted from Microcystis aeruginosa (Egyptian isolate): Comparison with some synthesized analogs. Int. J. Peptide Protein Res., 41: 1-7.

Bouaïcha, N., A. Chézeau, J. Turquet, J.P. Quod \& S. Puiseux-Dao. 2001. Morphological and toxicological variability of Prorocentrum lima clones isolated from four locations at South West Indian Ocean. Toxicon, 39: 1195-1202.

Boyer, S.L., V.R. Flechtner \& J.R. Johansen. 2001. Is the 16S23S rRNA internal transcribed spacer region a good tool for user in molecular systematics and population genetics? A case study in cyanobacteria. Mol. Biol. Evol., 18: 1057-1069.

Brittain, S., Z.A. Mohamed, J. Wang, V.K.B. Lehmannc, W.W. Carmichael \& K.L. Rinehartc. 2000. Isolation and characterization of microcystins from a River Nile strain of Oscillatoria tenuis Agardh ex Gomont. Toxicon, 38: 1759-1771.

Carmichael, W.W., S.M. Azevedo, J.S. An, R.J. Molica, E.M. Jochimsen, S. Lau, K.L. Rinehart, G.R. Shaw \& G.K. Eaglesham. 2001. Human fatalities from cyanobacteria: chemical and biological evidence for cyanotoxins. Environ. Health Perspect., 109:: 663-668.

Codd, G.A., J. Lindsay, F.M. Young, L.F. Morrison \& J.S. Metcalf. 2005. Harmful cyanobacteria from mass mortalities to management measures. In: Huisman J, Matthijis HCP \& PM Visser (Eds), Springer, Netherlands: 1-23.

Dittmann, E. \& T. Börner. 2005. Genetic contributions to the risk assessment of microcystin in the environment. Toxicol. Appl. Pharmacol., 203: 192-200.

Dittmann, E., B.A. Neilan, M. Erhard, H. Von Döhren \& T. Börner. 1997. Insertional mutagenesis of a peptide synthetase gene that is responsible for hepatotoxin production 
in the cyanobacterium Microcystis aeruginosa PCC7806. Mol. Biol., 26: 779-787.

El Herry, S., A. Fathalli, A. Jenhani-Ben Rejeb \& N. Bouaiïcha. 2008. Seasonal occurrence and toxicity of $\mathrm{Mi}$ crocystis spp. and Oscillatoria tenuis in the Lebna Dam, Tunisia. Water Res., 42: 1263-1273.

Humbert, J.F., D. Duris-Latour, B. Le Berre, H. Giraudet \& M.J. Salençon. 2005. Genetic diversity in Microcystis populations of a french storage reservoir assessed by sequencing of the 16S-23S rRNA intergenic spacer. Microb. Ecol., 49: 308-314.

Iteman, I., R. Rippka, N. Tandeau de Marsac \& M. Herdman. 2000. Comparison of conserved structural and regulatory domains within divergent $16 \mathrm{~S}$ rRNA-23S rRNA spacer sequences of cyanobacteria. Microbiology, 146: 1275-1286.

Janse, I., W.E.A. Kardinaal, M. Meima, J. Fastner, P.M. Visser \& G. Zwart. 2004. Toxic and nontoxic Microcystis colonies in natural populations can be differentiated on the basis of rRNA gene internal transcribed spacer diversity. Appl. Environ. Microbiol., 70:: 3979-3987.

Jochimsen, E.M., W.W. Carmichael, J.S. An, D.M. Cardo, S.T. Cookson, C.E.M. Holmes, M.B.D. Antunes, D.A. Demelo, T.M. Lyra, V.S.T. Barreto, S.M.F.O. Azevedo \& W.R. Jarvis. 1998. Liver failure and death after exposure to microcystins at a hemodialysis center in Brazil. New Engl. J. Med., 338: 873-878.

Komárek, J. \& K. Anagnostidis. 1999. Cyanoprokaryota, Part 1: Chroococcales. Süsswasserflora von Mitteleuropa, Bd 19/1, Spektrum Akademischer Verlag.

Kuiper-Goodman, T., I. Falconer \& J. Fitzgerald. 1999. Human health aspects, In: Chorus I. \& J Bartram (Eds). Toxic Cyanobacteria in water. A guide to their public Health consequences, monitoring and management. WHO Ed. E \& FN SPON: 113-153.

Laloui, W., K.A. Palinska, R. Rippka, F. Partensky, N. Tandeau de Marsac, M. Herdman \& I. Iteman. 2002. Genotyping of axenic and non-axenic isolates of the genus Prochlorococcus and the OMF-' Synechococcus' clade by size, sequence analysis or RFLP of the Internal Transcribed Spacer of the ribosomal operon. Microbiology, 148: 453-465.

Li, R., A. Yokota, J. Sugiyama, M. Watanabe, M. Hiroki \& M.M. Watanabe. 1998. Chemotaxonomy of planktonic cyanobacteria based on non-polar and 3-hydroxy fatty acid composition. Phycol. Res., 46: 21-28.

Lu, W., E.H. Evans, S.M. McColl \& V.A. Saunders. 1997. Identification of cyanobacteria by polymorphisms of PCRamplified ribosomal DNA spacer region. FEMS Microbiol. Lett., 153: 141-149.

Lyra, C., S. Suomalainen, M. Gugger, C. Vezie, P. Sundman, L. Paulin \& K. Sivonen. 2001. Molecular characterization of planktic cyanobacteria of Anabaena, Aphanizomenon, Microcystis and Planktothrix genera. Int. J. Syst. Evol. Microbiol., 51: 513-526.

Mikalsen, B., G. Boison, O.M. Skulberg, J. Fastner, W. Davies, T.M. Gabrielsen, K. Rudi \& K.S. Jakobsen. 2003. Natural variation in the microcystin synthetase operon mcy $\mathrm{ABC}$ and impact on microcystin production in Microcystis strains. J. Bacteriol., 185:: 2774-2785.

Mohamed, Z.A., W.W. Carmichael \& A.A. Hussein. 2003. Estimation of Microcystins in the freshwater fish Oreochromis niloticus in an Egyptian fish farm containing a Microcystis bloom. Environ. Toxicol., 18: 137-141.

Nasri, A.B., N. Bouaïcha \& J. Fastner. 2004. First report of a microcystin-containing bloom of the Cyanobacteria $\mathrm{Mi}$ crocystis spp. in Lake Oubeira, Eastern Algeria. Arch. Environ. Contam. Toxicol., 46: 197-202.

Nasri, H., N. Bouaïcha \& M. Kaid Harche. 2007. A new morphospecies of Microcystis sp. forming bloom in the Chef- fia Dam (Algeria): Seasonal variation of microcystin concentrations in the raw water and their removal in a fullscale treatment plant. Environ. Toxicol., 22: 347-356.

Neilan, B.A., D. Jacobs, T. Deldot, L.L. Blackall, P.R. Hawkins, P.T. Cox \& A.E. Goodman. 1997. Ribosomal-RNA sequences and evolutionary relationships among toxic and nontoxic cyanobacteria of the genus Microcystis. Int. J. Sys. Bacteriol., 47: 693-697.

Olsen, M.K., K.M. Gheri \& D.F. Walls. 1994. Bright squeezing from self-induced transparencies in dressed three-level atoms. Phys. Rev., A 50: 5289-5300.

Otsuka, S., S. Suda, R. Li, S Matsumoto \& M.M. Watanabe. 2000. Morphological variability of colonies of Microcystis morphospecies in culture. J. Gen. Appl. Microbiol., 46: 39-50.

Otsuka, S., S. Suda, R. Li, M. Watanabe, H. Oyaizu, S. Matsumoto \& M.M. Watanabe. 1999. Phylogenetic relationships between toxic and non-toxic strains of the genus Microcystis based on $16 \mathrm{~S}$ to $23 \mathrm{~S}$ internal transcribed spacer sequence. FEMS Microbiol. Lett., 172: 15-21.

Otsuka, S., S. Suda, R. Li, M. Watanabe, H. Oyaizu, S. Matsumoto \& M.M. Watanabe. 1998. 16S rDNA sequences and phylogenetic analyses of Microcystis strains with and without phycoerythrin. FEMS Microbiol. Lett., 164: 119-124.

Ouahid, Y., G. Pérez-Silva \& F.F. Del Campo. 2005. Identification of potentially toxic environmental Microcystis by individual and multiple PCR amplification of specific microcystin synthetase gene regions. Environ. Toxicol., 20: 235-242.

Oudra, B., M. Loudiki, V. Vasconcelos, B. Sabour, B. Sbiyyaa, K. Oufdou \& N. Mezrioui. 2002. Detection and quantification of microcystins from cyanobacteria strains isolated from reservoirs and ponds in Morocco. Environ. Toxicol., 17: 32-39.

Oudra, B., M. Loudiki, B. Sbiyyaa, R. Martins, V. Vasconcelos and N. Namikoshi. 2001. Isolation, characterization and quantification of microcystins (heptapeptides hepatotoxins) in Microcystis aeruginosa dominated bloom of Lalla Takeroust lake-reservoir (Morocco). Toxicon, 39: 1375-1381.

Pourria, S., A. De Andrade, J. Barbosa, R.L. Cavalcanti, V.T. Barreto, C.J. Ward, W. Preiser, G.K. Poon, G.H. Neild \& G.A. Codd. 1998. Fatal microcystin intoxication in haemodialysis unit in Caruaru, Brazil. Lancet, 352: 21-26.

Sabour, B., M. Loudiki, B. Oudra, V. Vasconcelos, R. Martins, S. Oubraim \& B. Fawzi. 2002. Toxicity and toxinology of Microcystis ichtyoblabe waterbloom occured in the Oued Mellah Lake (Morocco). Environ. Toxicol., 17: 24-31.

Sivonen, K. \& G. Jones. 1999. Cyanobacterial toxins. In: Chorus I. \& J. Bartram (Eds). Toxic Cyanobacteria in water. A guide to their public Health consequences, monitoring and management. WHO Ed. E \& FN SPON: 41-111.

Tillett, D., D.L. Parker \& B.A. Neilan. 2001. Detection of toxigenicity by a probe for the microcystin synthetase A gene (mcyA) of the cyanobacterial genus Microcystis, comparison of toxicities with $16 \mathrm{~S}$ rRNA and phycocyanin operon (phycocyanin intergenic spacer) phylogenies. Appl. Environ. Microbiol., 67: 2810-2818.

Via-Ordorika, L., J. Fastner, R. Kurmayer, M. Hisbergues, E. Dittmann, J. Komárek, M. Erhard \& I. Chorus. 2004. Distribution of microcystin-producing and non-microcystinproducing Microcystis sp. in European freshwater bodies: Detection of microcystins and microcystin genes in individual colonies. System. Appl. Microbiol., 27: 592-602.

Watanabe, M. 1996. Isolation, cultivation, and classification of bloom-forming Microcystis in Japan. In: Watanabe M.F., Harada K., Carmichael W.W. \& H. Fujiki (Eds), Toxic Microcystis. CRC Press, Boca Raton, FL:13-34. 